\title{
Public-private sector wage differentials in Germany: evidence from quantile regression ${ }^{+}$
}

\author{
Blaise Melly \\ Swiss Institute for International Economics and Applied Economic Research (SIAW), \\ University of St. Gallen
}

March 2003

Address for correspondence

Blaise Melly

Swiss Institute for International Economics and Applied Economic Research (SIAW)

University of St. Gallen

Bodanstrasse 8, 9000 St. Gallen, Switzerland

0041712242301

blaise.melly@unisg.ch

${ }^{+}$I thank Michael Lechner and the Centre for European Economic Research (ZEW), Mannheim, for letting me work with the full sample of the German Socio-Economic Panel (GSOEP). I am grateful for helpful comments to Michael Lechner, Ruth Miquel, seminar participants at University of Konstanz, the editor of this journal and an anonymous referee. All remaining errors are mine. 


\begin{abstract}
:
This paper measures and decomposes the differences in earnings distributions between public sector and private sector employees in Germany for the years 1984-2000. Two decomposition methods are used: Oaxaca decomposition using quantile regression and the decomposition proposed by Machado and Mata (2002). Both indicate that the public sector wage premium is highest at the lower end of the wage distribution and then decreases monotonically as we move up the wage distribution. At the mean or the median, wages are lower in the public sector for men but higher for women. Separate analyses by work experience and educational groups reveal that the most experienced employees and those with basic schooling do best in the public sector. All these results are stable over the 80 s and 90 s.
\end{abstract}

Keywords: Quantile regression, public-private wage differential, Germany.

JEL classification: J3, J45. 


\section{Introduction}

Public sector pay has always attracted policy attention. Obviously the size of the public sector wage bill has implications for both monetary and fiscal policy. The government remains by far the largest employer in Germany. In 2000, 4.91 million people or 13.4 percent of the labor force received his wage or salary from the public sector (Federal Statistical Office 2001). Furthermore, the wage settlements in the public sector could have a substantial impact over those in the private sector. Because of this spillover effect, the existence of a public sector wage premium may induce private sector employers to pay higher wages to their employees. The concern is that such general wage increases can jeopardize competitiveness in the global economy and further fuel inflation.

There are a number of reasons that earnings differential between the private and the public sector could exist. The public sector is subject to political constraints and not to profit constraints. Therefore the political system may have different objectives from those of the private sector. Issues of pay equity and fairness can survive in the political market place more than in the economic market place. Governments are also under pressure to be a model employer and not pay low wages to its less skilled workforce. Similarly, voters seem to refuse that high-level officials receive comparable remuneration to the high salaries of the private sector. Nevertheless, the pursuit of theses equity goals could have a serious impact on the efficiency of the labor market. If the government pays too much, employees in the private sector may decide to queue for relatively high-paying jobs in the public sector. Moreover, this policy leads to higher taxes or budget deficits. If the public sector pays wages that are too low, it will not find skilled and loyal employees. The consequences will be public services of poor quality.

Given these differences in the wage setting procedures and the possible consequences for the labor market, many researchers have sought to ascertain whether an identical employee working in the same job in the public and in the private sector would earn the same or a different amount. Early research comparing the earnings of public sector employees has been undertaken in the United States by Smith (1976 and 1977). She found that rates of pay were higher for public sector than private sector employees and that the earnings premium was larger for female than for male public sector employees. Subsequent research has taken up the same question as Smith and confirmed her findings. Ehrenberg and Schwarz (1986) and Gregory and Borland (1999) have surveyed this voluminous literature. Such wage comparisons using German data are not as numerous. Dustmann and Van Soest (1997) used data from the German Socio-Economic Panel for the years 1984-93 to analyze developments and differences in public and private sector wage distributions. They found that conditional wages are higher in the private sector for males but higher in the public sector for females. Dustmann and Van Soest (1998) estimated switching regression models for males and models that endogenise education. Their later results are stronger than the results that they reported in 1997.

Poterba and Rueben (1995) were the first to apply quantile regression to study publicprivate wage differentials. This is a natural arena for quantile regression, since there is a 
suspicion that the public sector compresses the distribution of earnings of employees who work in that sector relative to private sector employees. Therefore, the least squares estimate of the mean public sector wage premium gives an incomplete picture of the conditional distribution. Evidence to this effect is available for Canada (Mueller 1998), UK (Disney and Gosling 1998) and Zambia (Nielsen and Rosholm 2001). Quantile regression has apparently not yet been applied to study the wage structure in the private and public sectors in Germany. This is the object of this paper.

Section 2 describes the data set along with some descriptive statistics. The two following sections decompose the differences in the wage distributions between the public and the private sector into an explained and an unexplained component. In section 3, the Oaxaca decomposition using quantile regression is applied and, in section 4, the methodology proposed by Machado and Mata (2002) is presented and used. Section 5 shows how the wage premium has evolved from 1984 to 2000. Finally section 6 gives some concluding remarks.

\section{Data description}

The analysis in this paper draws on data from the German Socio-Economic Panel (GSOEP) ${ }^{1}$. In this and the two following sections, we focus on 2000. In section 5 we analyze the evolution from 1984 to 2000. After reunification, the panel was extended to include the eastern part of Germany, but we focus here on West Germany only because undeniable economic differences subsist between East and West Germany. Since many public sector jobs are not open to foreign nationals, the analysis is based on the subsample of Germans only. Furthermore, the sample is restricted to include those who were between 18 and 65 years old and were in full-time or part-time employment. Finally, all observations with a missing value for one of the variables have been excluded. The final data set has 2972 observations.

As the sample includes only wage earners, the results must be interpreted conditional on the selected sample. Issues of sample selection bias and the potential problem of endogeneity of sector choice and education are considered outside the scope of the present paper, which concentrates on distributional aspects. This is, of course, a more descriptive approach and some caution must be exercised in interpreting the results.

Table A.1 in Appendix describes the variables we use for our descriptive analyses and in the decompositions. Table A.2 presents descriptive statistics for male and female public and private sector employees. Means of relevant variables show that average hourly earnings are higher in the public sector than in the private sector. They also show that public sector employees are, on average, better educated than private sector employees. For instance, 19 per cent of the employees in the public sector have achieved a university degree (Ed level 6), while they are only 9 per cent in the private sector. Public sector employees have acquired more labor market experience and tenure, too. These differences in work experience, education and tenure may explain the higher average wages of public sector employees.

\footnotetext{
${ }^{1}$ For an English language description of the GSOEP see SOEP Group (2001).
} 
Another part of disparity between average compensation in the public and the private sectors may be due to the greater concentration of professionals and clerks in the public sector.

Table 1: Percentiles of the log wage

\begin{tabular}{|ll|c|c|c|c|c|c|}
\hline & & $10 \%$ & $25 \%$ & $50 \%$ & $75 \%$ & $90 \%$ & $0.9-0.1$ spread \\
\hline Males & Public sector & 2.907 & 3.154 & 3.376 & 3.585 & 3.780 & 0.873 \\
& Private sector & 2.724 & 3.030 & 3.293 & 3.586 & 3.861 & 1.137 \\
\hline Females & Public sector & 2.597 & 2.918 & 3.171 & 3.364 & 3.570 & 0.973 \\
& Private sector & 2.213 & 2.663 & 2.967 & 3.241 & 3.497 & 1.284 \\
\hline
\end{tabular}

To get a picture of the unconditional wage dispersion in each sector, the $10^{\text {th }}, 25^{\text {th }}, 50^{\text {th }}$, $75^{\text {th }}$ and $90^{\text {th }}$ percentiles of the log wage are displayed in Table 1. A measure of the wage dispersion, the 0.9-0.1 spread, is also shown in this table. For both genders, this spread is clearly higher in the private sector than in the public sector, indicating that the unadjusted earnings are more compressed in the public sector. For males, public sector employees at the $1^{\text {st }}$ decile of the public sector earnings distribution enjoy an earnings advantage over private sector employees at the same point in the private sector distribution of wages; but the reverse holds for employees at the $9^{\text {th }}$ decile of the public sector and private sector earnings distribution. With "higher floors" and "lower ceilings", the public sector compresses the unconditional wage distribution.

Figure 1: Kernel density estimates of the wage distributions for men
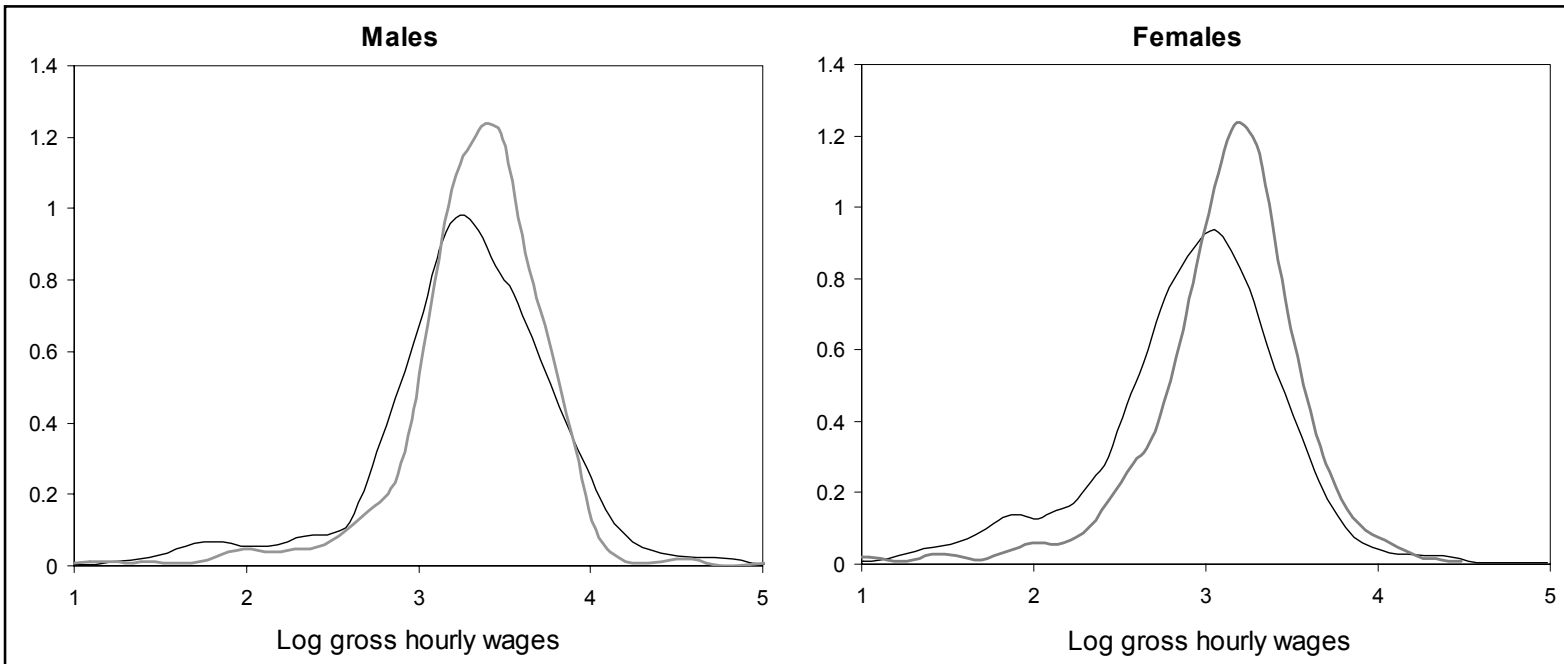

- Private sector

- Public sector

Note: Epanechnikov kernel density estimates; the bandwidths were chosen using Silverman's rule of thumb.

A first visual summary of the public and private sector wage distributions is provided in Figures 1 and 2 for men and women respectively. The density functions were estimated using an Epanechnikov kernel estimator. Silverman's rule of thumb was used to choose the bandwidths. It can be seen from these figures that the distributions are quite distinct between sectors. For both genders, the public sector earnings distribution is characterized by a higher density function around the mode and a lower dispersion. Of course, differences in earnings dispersion between public and private sector employees using raw earnings data may 
confound the effects of a worker's sector of employment with the effects of differences in the distribution of worker characteristics between sectors. In order to control for these differences and to study conditional wages and wage differentials, we will estimate wage regressions in the next sections.

\section{Oaxaca decomposition using quantile regression}

\subsection{Methodology}

OLS and most statistical techniques focus on mean effects. They restrict the effect of the covariates to operate in the form of a simple "location shift". However, the descriptive statistics in the preceding section show that the impact of the public sector on the distribution of the wages is probably more complex. The quantile regression model introduced by Koenker and Bassett (1978) is more flexible than OLS and allows to study the effects of a covariate on the whole conditional distribution of the dependent variable.

Let $y_{i}$ be the log wage of worker $i$ and $X_{i}$ a vector of covariates representing the individual characteristics. The statistical model used in this paper specifies the $\theta$ th quantile of the conditional distribution of $y_{i}$ given $X_{i}$ as a linear function of the covariates,

$$
\operatorname{Quant}_{\theta}\left(y_{i} \mid X_{i}\right)=X_{i} \beta_{\theta}, \theta \in(0,1) .
$$

As shown by Koenker and Bassett (1978 and 1982), the quantile regression estimator of $\beta_{\theta}$ solves the following minimization problem

$$
\hat{\beta}_{\theta}=\underset{\beta}{\arg \min }\left[\sum_{i: y_{i} \geq X_{i} \beta} \theta\left|y_{i}-X_{i} \beta\right|+\sum_{i: y_{i}<X_{i} \beta}(1-\theta)\left|y_{i}-X_{i} \beta\right|\right] .
$$

This problem can be shown to fit into a GMM framework which has been used to prove consistency and asymptotic normality of $\hat{\beta}_{\theta}$ and to find its asymptotic covariance matrix (Buchinsky 1991 and 1998). There are several alternative schemes for estimating the covariance matrix. In the present application it is obtained by bootstrap, which is known to be consistent (Fitzenberger 1998). There is a rapidly expanding empirical quantile regression literature. Koenker and Hallock (2001) have recently surveyed it.

As in studies of sex, race or union wage differentials, the basic methodological approach would be to estimate an earnings regression using pooled data for public sector and private sector employees and include a dummy variable for the worker's sector of employment. One problem with the dummy variable approach is that the returns to productivity-related characteristics and job attributes are constrained to be equal across sectors. The effect of a worker's sector of employment (public or private) is limited to be an intercept effect. To test if this restriction is plausible, we have estimated a fully interacted model using pooled data and have then performed a Wald test. The null hypothesis that all interaction terms are zero is rejected for all estimated quantiles at the $1 \%$ level of significance. Therefore we will not present results using this technique.

An alternative approach involves estimating separate earnings functions for individuals in the public and private sectors. Following Blinder (1973) and Oaxaca (1973), the difference in 
average earnings between workers in each sector can be decomposed into differences in personal characteristics and differences in coefficients. A disadvantage of this approach is that it only focuses on differences at the means of the two earnings distributions. However, the decomposition technique may be combined with quantile regressions to determine the rent component at various points in the wage distribution (Mueller 1998 and Garcia et al. 2001).

Formally, the first step is to estimate

$$
y_{i}^{j}=X_{i} \beta_{\theta}^{j}+\text { residual }_{\theta, i} \quad j=\text { public, private, } \theta \in(0,1)
$$

by quantile regression separately in each sector. We can then decompose the difference in the $\theta$ th quantile of the log wage distribution between the public and private sector as follows

$$
Q_{\theta}\left(y^{p u b}\right)-Q_{\theta}\left(y^{p r i v}\right)=\left(\bar{X}^{p u b}-\bar{X}^{p r i v}\right) \hat{\beta}_{\theta}^{p r i v}+\bar{X}^{p u b}\left(\hat{\beta}_{\theta}^{p u b}-\hat{\beta}_{\theta}^{p r i v}\right)+\text { residual }
$$

where $Q_{\theta}\left(y^{j}\right)$ is the $\theta$ th empirical quantile of the wage distribution, $\bar{X}^{j}$ the vector of average characteristics of employees and $\hat{\beta}^{\mathrm{j}}$ the estimated vector of returns to worker characteristics in sector $j$. The first term on the right-hand side is the component of the log wage differential due to differences in endowments between public and private sector employees. The second term shows the component due to differences in returns to these endowments. Note that if the properties of the OLS estimators ensure that the predicted log wage evaluated at the sample average vector of characteristics is exactly equal to the sample average $\log$ wage, the estimators for the quantile regression model do not have any comparable properties. That is, the conditional quantile evaluated at the mean of the covariates is not equal to the unconditional quantile.

\subsection{Empirical results}

Separate earnings equations for the public and the private sector and for both sexes have been estimated using standard OLS and quantile regressions ${ }^{2}$. The vector of regressors $X_{i}$ includes experience (specified in a quartic form), job tenure, marital status, part-time status, education and occupation. The descriptive statistics of these variables are given in Table A.2. The reference educational category is Ed level 1 and the reference occupational category is Professional.

Using equation (4), total log wage differentials are broken into rent and characteristics differentials. Tables 2 and 3 show the decomposition of public/private sector earnings differential for males and females respectively. The upper part of the tables decomposes the sectorial differential in the predicted log wage into rent payment (coefficients component) and justifiable differential (characteristics component). The lower part of the tables shows how much of the total difference in characteristics is due to specific sets of variables.

\footnotetext{
${ }^{2}$ The detailed results are available upon request from the author.
} 
Table 2: Oaxaca decomposition of the public/private sector wage differential for men

\begin{tabular}{|l|cccccc|}
\hline & OLS & $\theta=0.10$ & $\theta=0.25$ & $\theta=0.50$ & $\theta=0.75$ & $\theta=0.90$ \\
\hline Differences in ln(wage) & $6.7(2.7)$ & $18.3(7.4)$ & $12.4(2.6)$ & $8.3(2.3)$ & $-0.1(3.1)$ & $-8.1(3)$ \\
Rent payment & $-7.8(2.2)$ & $3.1(4.3)$ & $-1.6(3)$ & $-8.4(2.8)$ & $-12.8(2.9)$ & $-17.2(4.4)$ \\
Char. differential & $14.5(2.6)$ & $17(3.6)$ & $14.4(2.9)$ & $13.6(2.9)$ & $13.6(2.6)$ & $12.1(3.1)$ \\
\hline $\begin{array}{l}\text { Differences due to } \\
\text { characteristics: }\end{array}$ & & & & & & \\
Experience & $2(1.1)$ & $0.9(1.4)$ & $1.7(1.1)$ & $2.2(1.1)$ & $2.2(1)$ & $3.2(1.3)$ \\
Education & $7.4(1.3)$ & $7.7(2)$ & $7.9(1.4)$ & $7.9(1.3)$ & $7(1.2)$ & $8.4(1.7)$ \\
Occupation & $0.5(1.3)$ & $1.7(2.1)$ & $-0.4(1.6)$ & $-0.3(1.8)$ & $0.6(1.6)$ & $-1(1.9)$ \\
Tenure & $4.5(1)$ & $6.4(1.5)$ & $5.5(1.1)$ & $4.1(0.9)$ & $3.8(1)$ & $1.2(1.2)$ \\
Married & $0.4(0.2)$ & $0.6(0.5)$ & $0.4(0.3)$ & $0.2(0.2)$ & $0.2(0.2)$ & $0.3(0.3)$ \\
Part-time & $-0.3(0.3)$ & $-0.3(0.4)$ & $-0.6(0.4)$ & $-0.5(0.4)$ & $-0.2(0.3)$ & $-0.1(0.5)$ \\
\hline
\end{tabular}

Note: All numbers are in percent. The decompositions are based on equation (4). Totals may not sum exactly due to rounding. Bootstrap standard errors are given in parenthesis (1000 replications).

The rent payment estimated by the Oaxaca/Binder decomposition (OLS) equals $-7.8 \%$ for men, indicating that wages in the public sector are about 8 per cent lower than wages in the private sector. For females, on the other hand, the public sector appears to pay a significant premium of $7.8 \%$. Both coefficients are strongly significant. If the distribution of the error terms is symmetric, mean and median regressions estimate the same quantity. The OLS and LAD $(\theta=0.5)$ estimates are actually similar. At the median, the public sector pay premium is $-8.4 \%$ for men and $5.2 \%$ for women. Again, both coefficients are significant. These results are similar to that of Dustmann and Van Soest (1997).

The OLS regression does not consider the possibility that the distribution of actual wages around their predicted values differ across sectors. In fact, both the unconditional and the conditional wage distribution in the public sector are more compressed than those in the private sector. Therefore, to complete the analysis, Table 2 and 3 present also estimates from decomposition using quantile regressions with $\theta=0.10,0.25,0.75$ and 0.90 . The estimated public sector wage premium varies strongly with $\theta$. For males this premium decreases from $3.1 \%$ at $\theta=0.10$ to $-17.2 \%$ at $\theta=0.90$. For females, this premium varies from $13.3 \%$ at $\theta=0.10$ to $-5.8 \%$ at $\theta=0.90$. The quantile regressions reveal dispersion in the public sector that cannot be captured using OLS. This sector compresses the pay dispersion and, therefore, reduces the within-group pay inequality.

The characteristics component shows that male public sector employees should earn more than private sector employees at all points of the wage distribution. Compared with private sector employees, public sector workers are better educated and have more years of job tenure and more experience. We do not observe substantial differences in occupations or part-time employment. The characteristics differential decreases as we move up the wage distribution, in particular because of the declining importance of job tenure. This shows that the more 
compressed wage distribution in the public sector is partly due to differences in characteristics.

Table 3: Oaxaca decomposition of the public/private sector wage differential for women

\begin{tabular}{|l|cccccc|}
\hline & OLS & $\theta=0.10$ & $\theta=0.25$ & $\theta=0.50$ & $\theta=0.75$ & $\theta=0.90$ \\
\hline Differences in ln(wage) & $20.4(2.9)$ & $38.4(7.6)$ & $25.5(3)$ & $20.4(2.6)$ & $12.3(3.1)$ & $7.3(3.5)$ \\
& $7.8(2.9)$ & $13.3(7.2)$ & $14.5(4)$ & $5.2(3.1)$ & $0.7(2.9)$ & $-5.8(4)$ \\
Rent payment & $12.6(2.7)$ & $17.4(4.3)$ & $15(3.4)$ & $11.8(2.7)$ & $13.3(2.5)$ & $14(2.7)$ \\
Char. differential & & & & & & \\
Differences due to & & & & & & \\
characteristics & & & & & & \\
Experience & $-0.6(1.1)$ & $-0.7(1.3)$ & $-0.7(1.2)$ & $-0.7(1.1)$ & $-0.3(0.8)$ & $-0.2(0.8)$ \\
Education & $5(1.2)$ & $4.3(1.6)$ & $4.2(1.4)$ & $2.7(1.2)$ & $5.6(1.4)$ & $6.8(1.9)$ \\
Occupation & $7(1.9)$ & $12.3(3.4)$ & $9.1(2.4)$ & $7.8(2)$ & $5.6(1.9)$ & $5.4(2.2)$ \\
Tenure & $2(0.8)$ & $2.8(1.4)$ & $3.3(1.1)$ & $2.7(1)$ & $2.8(0.8)$ & $2.5(0.8)$ \\
Married & $-0.2(0.2)$ & $-0.5(0.5)$ & $-0.3(0.3)$ & $-0(0.1)$ & $-0(0.1)$ & $-0.1(0.2)$ \\
Part-time & $-0.6(0.5)$ & $-0.9(0.9)$ & $-0.8(0.7)$ & $-0.6(0.5)$ & $-0.4(0.4)$ & $-0.4(0.4)$ \\
\hline
\end{tabular}

Note: All numbers are in percent. The decompositions are based on equation (4). Totals may not sum exactly due to rounding. Bootstrap standard errors are given in parenthesis (1000 replications).

The breakdown of the characteristics component of females is very different from that of males. Differences in experience and the part-time status are of less importance for women than for men. Occupations, which were insignificant for men, are now the characteristics that explain the most part of the justifiable differential. Thus, the decomposition of the wage differential shows that there are no occupational differences between the private and the public sector for men but there are important differences for women. It is likely to regard differences in the occupational distribution of males and females as indicative of discrimination and not of differential tastes by women for the jobs they want to hold. Gregory and Borland (1999) have found that the gender occupational integration proceeds more rapidly in the public sector than in the private sector. For example, $40 \%$ of the women in the public sector are employed in the professional occupational group when they are only $14 \%$ in the private sector. For women in professional occupations, the public sector is capital as employment opportunities: $54 \%$ are publicly employed. For men, this proportion is only $31 \%$. Thus, it seems that occupational discrimination is less in the public sector than in the private sector.

These results suggest that the gender gap in wage could be smaller in public employment than in private employment. To confirm or reject this hypothesis, the gender pay differential has been estimated separately for each sector by decomposing the wage differential (using the male coefficients as nondiscriminatory wage structure). Table 4 shown the estimated gender gaps along with their standard errors obtained by bootstrapping. The magnitude of pay discrimination by gender is clearly (more than $10 \%$ ) smaller in the public than in the private sector. 
Table 4: Unexplained gender wage gap in the private and public sectors

\begin{tabular}{|l|cccccc|}
\hline & OLS & $\theta=0.10$ & $\theta=0.25$ & $\theta=0.50$ & $\theta=0.75$ & $\theta=0.90$ \\
\hline Private sector & $-22(3.6)$ & $-24.6(7)$ & $-21.9(4.8)$ & $-12.8(4.9)$ & $-20.3(4.8)$ & $-22.9(7.5)$ \\
Public sector & $-3.3(4.2)$ & $-10.7(7.8)$ & $-4(6)$ & $-0(5.7)$ & $-8.6(6.2)$ & $-17.8(6.9)$ \\
\hline
\end{tabular}

Note: Oaxaca decompositions. All numbers are in percent. Totals may not sum exactly due to rounding. Bootstrap standard errors are given in parenthesis (1000 replications).

Interestingly, these results contradict standard economic theory. Unlike the private sector, the public sector is not subject to profit constraints. Becker (1971), for instance, suggests that profit-maximizing behavior is incompatible with the existence of discrimination. Following this argument, we might expect the adjusted male-female earnings differential to be smaller in the private sector. Why should nevertheless the male-female earnings differential be smaller for public sector than private sector employees? First, the pay system for all public sector employees is uniform and centralized. It is regulated in the Federal Act on the Remuneration of Civil Servants (Bundesbesoldungsgesetz), which requires equal pay for all individuals with the same seniority and qualifications who are employed in a given job. Equal opportunity and anti-discrimination policies are therefore more effectively implemented in public sector than private sector labor markets. Second, we have found that the distribution of wages is more compressed in the public than in the private sector. Blau and Kahn (1992) have shown that the more compressed the pay distribution, the lower the level of gender discrimination. Their evidence rely on cross-national comparisons of the impact of different wage distribution on the gender wage inequality. Here, there are two different pay systems within one land.

A consequence of this large wage advantage of females in the public sector is the overrepresentation of women in the public sector. They represent $50 \%$ of the public sector employees but only $41 \%$ of the private sector employees. Whether this wage policy is efficient or not depends on the interpretation of the gender earnings differentials. If it is believed that wage discrimination against females in private sector labor markets is causing inefficient resource allocation decisions, the presence of the public sector wage premium for women will reduce the degree of wage discrimination and improve the efficiency of the labor market.

\section{Machado/Mata decomposition}

\subsection{Methodology}

The decomposition method described in the preceding section evaluates the conditional quantiles at the covariates sample mean. We see two reasons for this choice. First, it makes this decomposition very similar with the Oaxaca decomposition. Second, as proved in Bassett and Koenker (1982), $\theta_{1}<\theta_{2} \Rightarrow \bar{X} \hat{\beta}_{\theta_{1}}<\bar{X} \hat{\beta}_{\theta_{2}}$ while the monotonicity of the conditional quantiles evaluated at another point is not guaranteed.

However, by considering only the mean of the regressors, we may miss some important factors explaining the difference between two distributions. Assume, for example, that the 
covariate sample means are the same in both sectors but that the variance is much higher in the second sector. Then, ceteris paribus, the distribution of the dependent variable will also have a higher variance in the second sector but we will not be able to analyse this difference with the decomposition of section 3.

Machado and Mata (2002) propose an alternative decomposition procedure which combines quantile regression and a bootstrap approach. First, in the quantile regression model the conditional quantiles of $y$ are given by (1) and can be estimated by quantile regression. The second idea underlying their technique is the probability integral transformation theorem from elementary statistics: If $U$ is uniformly distributed on $[0,1]$, then $F^{-1}(U)$ has distribution $\mathrm{F}$. Thus, for a given $X_{i}$ and a random $\theta \sim U[0,1], X_{i} \beta_{\theta}$ has the same distribution as $y_{i} \mid X_{i}$. If, instead of keeping $X_{i}$ fixed, we draw a random $X$ from the population, $X \beta_{\theta}$ has the same distribution as $y$. Formally, the estimation procedure involves 4 steps:

1. Generate a random sample of size $m$ from a $U[0,1]: u_{1}, \ldots, u_{m}$.

2. Estimate for each sector $\mathrm{m}$ different quantile regression coefficients: $\hat{\beta}_{u_{i}}^{p u b}, \hat{\beta}_{u_{i}}^{\text {pub }} ; i=1, \ldots, m$.

3. Generate for each sector a random sample of size $m$ with replacement from the covariates of $\mathrm{X}$, denoted by $\left\{\tilde{X}_{i}^{p u b}\right\}_{i=1}^{m}$ and $\left\{\tilde{X}_{i}^{\text {priv }}\right\}_{i=1}^{m}$.

4. $\quad\left\{\tilde{y}_{i}^{p u b}=\tilde{X}_{i}^{p u b} \hat{\beta}_{u_{i}}^{p u b}\right\}_{i=1}^{m}$ and $\left\{\tilde{y}_{i}^{\text {priv }}=\tilde{X}_{i}^{\text {priv }} \hat{\beta}_{u_{i}}^{\text {priv }}\right\}_{i=1}^{m}$ are random sample of size $\mathrm{m}$ from the marginal wage distributions of $y$ consistent with the linear model defined by (1).

5. Generate a random sample of the counterfactual distribution. $\left\{\tilde{y}_{i}^{c f}=\tilde{X}_{i}^{p u b} \hat{\beta}_{u_{i}}^{p r i v}\right\}_{i=1}^{m}$ is a random sample from the wage distribution that would have prevailed in the private sector if all covariates had been distributed as in the public sector.

Now we can decompose the change of any statistics from one sector to the other into the contribution of the coefficients and the contribution of the covariates. Machado and Mata (2002) analyze the changes in the wage density. In order to simplify the comparison with the Oaxaca decomposition, we will decompose the quantiles of the wage distribution:

$$
Q_{\theta}\left(y^{p u b}\right)-Q_{\theta}\left(y^{p r i v}\right)=\left[Q_{\theta}\left(\tilde{y}^{p u b}\right)-Q_{\theta}\left(\tilde{y}^{c f}\right)\right]+\left[Q_{\theta}\left(\tilde{y}^{c f}\right)-Q_{\theta}\left(\tilde{y}^{\text {priv }}\right)\right]+\text { residual }
$$

The first term is the contribution of the coefficients and the second term is the contribution of the covariates to the difference between the $\theta$ th quantile of the public sector wage distribution and the $\theta$ th quantile of the private sector wage distribution. Note that a residual term arises because the sample is randomly generated but should asymptotically vanish.

\subsection{Public sector wage premium}

In order to decompose the differences in the wage distribution into rent payment (differences in the coefficients) and characteristics differential (differences in the workers attributes), we follows the procedure described in section 4.1 with the number of replications, 
$m$, set to 4500 . The covariates are the same as in section 3 . The results are summarized in Figure 2, which plots the decomposition defined in (5) for $\theta=0.01, \ldots, 0.99$ for males and females.

The wage premia patterns are generally consistent with those found in section 3: the public sector wage premium tends to decline as the quantiles increases. The main difference is that we observe greater dispersion between quantiles, with higher rent premia estimates at lower quantiles and lower estimates at higher quantiles. The results for females, for example, show a public sector rent premium of $21.9 \%$ at $\theta=0.1$ and a wage penalty of $8.2 \%$ at $\theta=0.9$. The comparable results from Table 3 are $13.3 \%$ and $5.8 \%$, respectively. The relative greater dispersion occurs also for males. If we integrate the rent premium over all estimated quantiles, we obtain a mean premium of $-6.6 \%$ for men and $6.9 \%$ for women, which is almost exactly the same as the Oaxaca/Blinder decomposition of section 3. On the contrary of the wage premium, the characteristics differential seems to be stable over the wage distribution and doesn't vary with the quantile. Its mean is about $15 \%$ for both genders.

Figure 2: Machado/Mata decomposition of the public/private sector wage differential

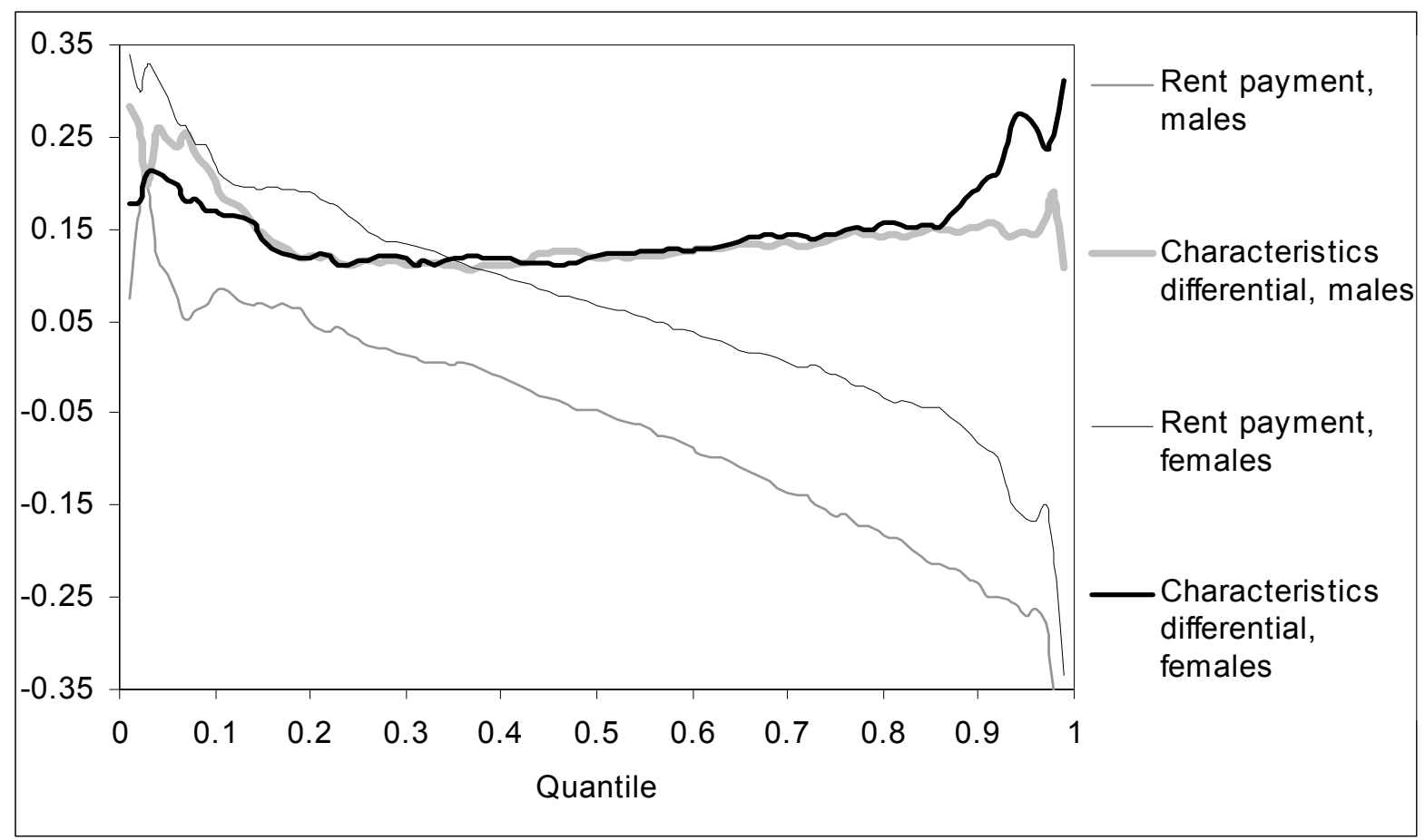

Note: Variables controlled for in the regressions are education, experience, ocupation, marital status, tenure and part-time status.

\subsection{Public sector wage premium by educational attainment}

Since the wage differential may vary across education levels, the public wage premium is now estimated separately for four ranges of schooling: Low education (corresponds to Ed level 1 and 2), Medium education (Ed level 3), High education (Ed level 4 and 5) and University (Ed level 6 ). The other regressors and the number of replications are the same as above. Figure 3 combine the results by qualification and quantile to look at the impact of public sector status on pay within and between educational groups. Only the results for $\theta \in(0.1,0.9)$ are plotted. 
The left-hand panel of Figure 3 provides the information for men. Quantile regression estimates show the same pattern for the 4 educational categories: the public sector premium declines as we move up the income distribution. Thus, the story of Figure 2 is confirmed: the public sector reduces the within-group inequality by compressing the wage distribution. The comparison of the wage premia for the four educational groups at the same quantile, equal which one, shows that the public sector wage premium decreases monotonically as the educational qualification increases. If we integrate the wage premia over all quantiles, the mean wage premium falls from $4 \%$ for the lowest education group at $-2 \%$ for the second group, $-11 \%$ for the third and $-24 \%$ for the top education category. Since the average wage increases with the number of years of schooling, there is an equalizing effect between educational groups attached to public sector status. The political pressure on the government not to pay low wages to its less skilled employees could explain why the return to education is higher in the private then in the public sector.

Figure 3: Public sector wage premium by educational attainment

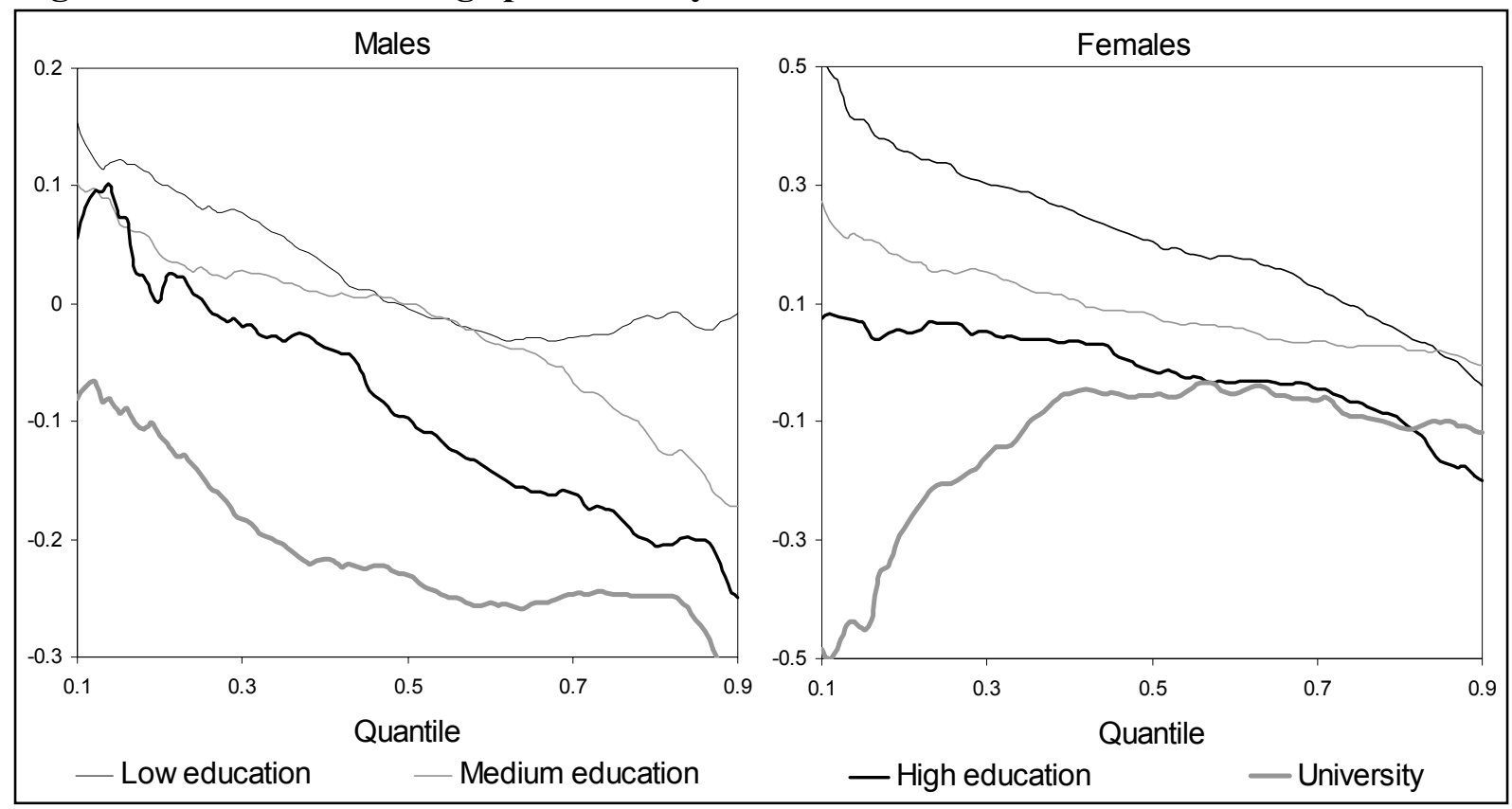

Note: Machado/Mata decomposition. Variables controlled for in the regressions are experience, occupation, marital status, tenure and part-time status.

The right-hand panel of Figure 3 illustrates the results for women. For the three lowest education categories, there is again evidence of a negative gradient in public sector premium across the income quantiles. For women with a university degree, the evidence of withingroup equalization of pay within the public sector is not apparent. As for men, there is evidence of an equalizing effect between groups attached to public sector status. While the level of the public sector wage premium is about $15 \%$ higher for women than for men, the differences between the educational levels are similar for both sexes. Thus, it seems that the government tends to be a model employer and refuses to pay low wages to its less educated employees. An implicit minimum wage in the public sector arises from this policy. Similarly, the government has the tendency to underpay its most skilled workforce. Very high salaries in the public sector seem to be not accepted by voters. 


\subsection{Public sector wage premium by levels of experience}

The public sector wage premium may also vary across different levels of experience. The observations are now segmented in four experience groups: those with less than 11 years of experience, 11-20 years, 21-30 years and more than 30 years. The other regressors and the number of replications are the same as above. Figure 4 combines the results by experience and quantile in the same way as Figure 3 did.

With a few exceptions, we observe again the equalizing effect of the public sector relative to the private sector, with a negative gradient of premiums as we move up the income distribution. The public sector wage premiums tend to be positive at the low quantiles and negative at the high quantiles. The less experienced groups seem to make exceptions. Here, there is no evidence of a change in the coefficient across the conditional wage distribution.

\section{Figure 4: Public sector wage premium by levels of experience}

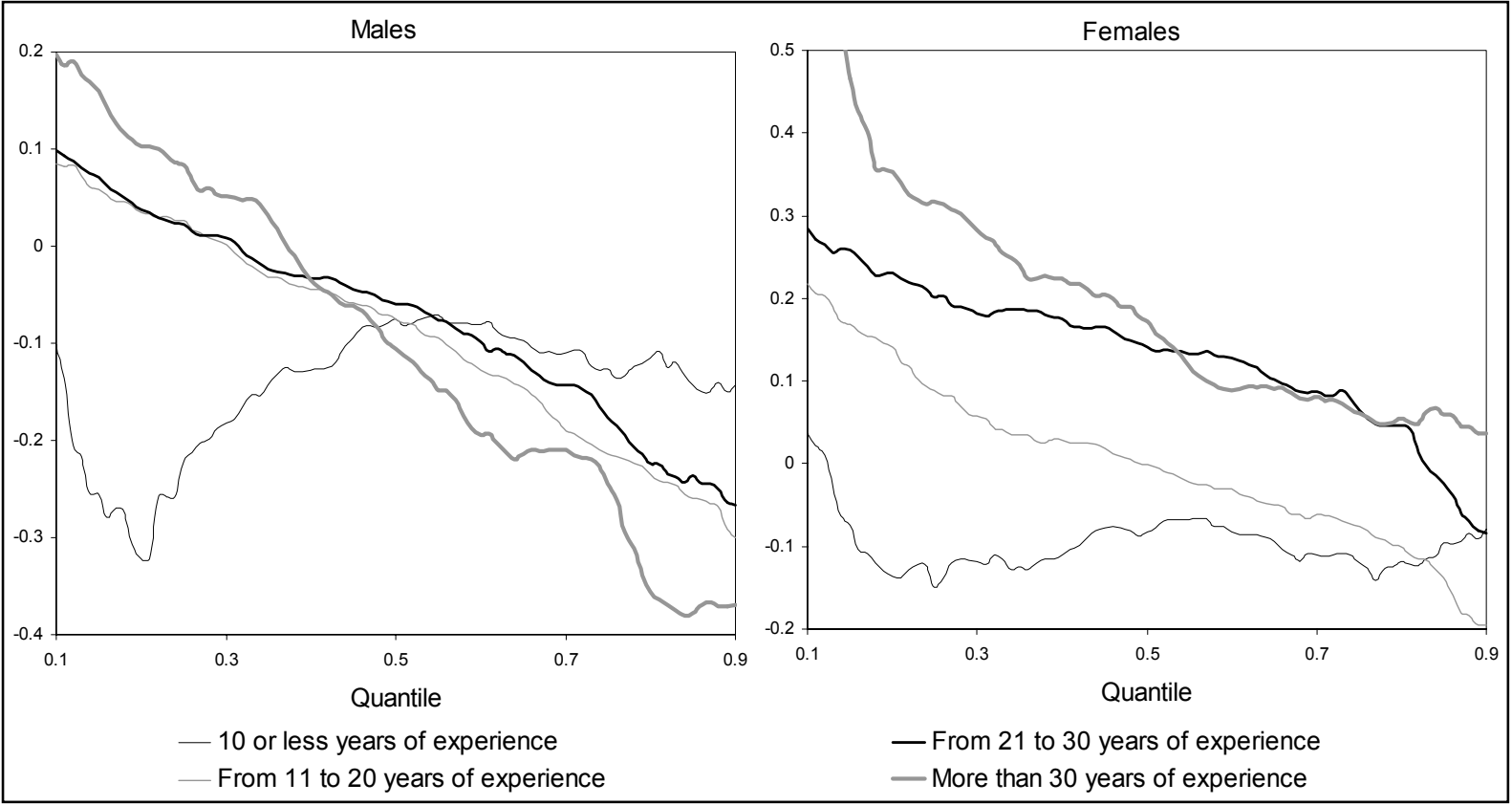

Note: Machado/Mata decomposition. Variables controlled for in the regressions are education, occupation, marital status, tenure and part-time status.

If we compare the level of the public sector wage premium across experience groups for men, it seems that the premium does not vary with the experience of the workers. On the contrary, the level of the public sector wage premium depends significantly on experience for women. The mean public sector wage premium is $-10 \%$ for the least experienced groups and increases monotonically to $24 \%$ for the most experienced groups. This difference between both sectors could be explained by the rigid hierarchical pay structure in the public sector. Salaries increase more or less mechanically with seniority. Wage decreases are difficult if not impossible. Moreover, a part of the discrimination of women takes the form of slower promotion rates. The centralized pay system in the public sector could reduce this form of discrimination. On the other hand, it may be easier to retain the same job after a maternity break or to change from full-time employment to part-time employment in the public sector. Therefore, females in the public sector could have more human capital than females in the private sector with the same age and the same education level (Dustmann and Van Soest 
1997). It should be noted, however, that the experience pattern reflects a combination of age, experience and cohort effect.

\section{Evolution over time}

Differences in the cyclical responsiveness of earnings of public sector and private sector employees may induce short-run changes of the public sector wage premium. Earnings of private sector employees generally vary pro-cyclically. Thus, if the pay structure is less flexible in the public sector and cannot react after an economic boom or a crisis, the public sector wage premium will vary counter-cyclically. Borjas (1984) presents another theory of why public/private earnings differential may vary over time. In his model, electoral wage cycles are generated as a result of optimizing behavior on the part of voters, bureaucrats, and the government. His empirical analysis for USA indicates that federal wage rates rise significantly more in election years.

Figure 5: Evolution of the public sector pay premium from 1984 until 2000

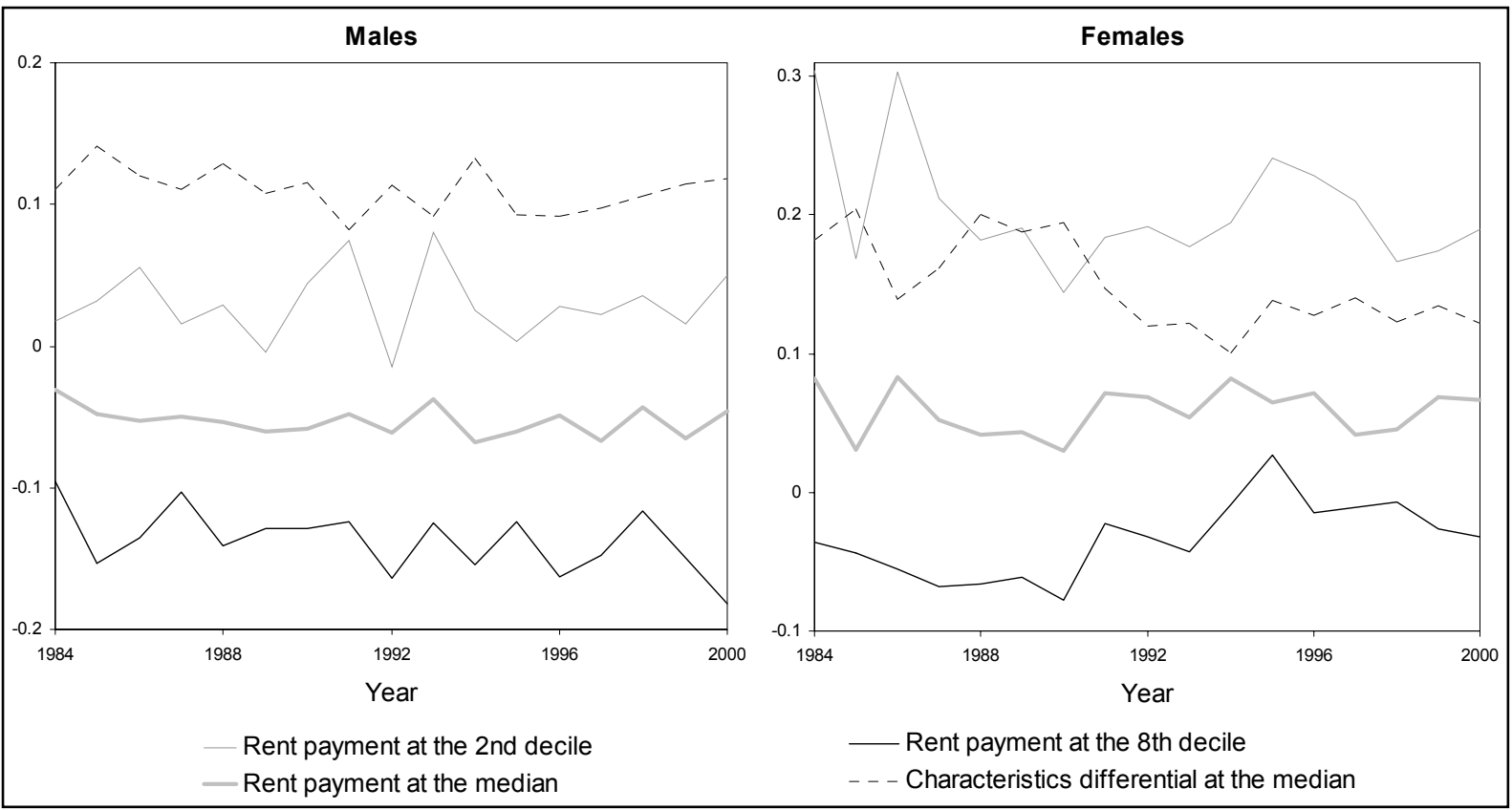

Note: Machado/Mata decomposition. Variables controlled for in the regressions are education, experience, ocupation, marital status, tenure and part-time status.

Therefore, it would be restrictive to study the issue of wage inequality between the public and the private sector based on only one cross-section of data and we expand now the analysis on the first 17 years of the SOEP. The same procedure as in section 4 has been applied for each of the 17 years. A concise visual summary is given in Figure 5. Since the characteristics differential is almost the same at all quantiles, only the estimate for $\theta=0.5$ is shown. The estimates of the rent payment are given for $\theta=0.2,0.5$ and 0.8 .

Remarkable in this figure is the extreme stability of the estimates during almost 2 decades. It is very difficult to find a trend or a cyclical component in these time series. All attempts to link the public sector pay premium with an economic or a political cycle were also unsuccessful. The results for different experience or education categories (not plotted) are also 
stable although the variance of the estimates is higher.This parallelism between public and private sector wages probably reflect the structure of wage negotiation in Germany. Collective bargaining agreements cover practically all areas of the public and the private sector. Wages of public sector workers are not formally linked with those in the private sector but indirectly they are since the negotiated results of the large private sector unions are often taken as a bench-mark for the public sector.

\section{Conclusions and policy implications}

The differences in the wage distribution between the public and the private sector have been decomposed into an explained and unexplained component using two different methodologies. The first is a simple combination of the Oaxaca/Blinder decomposition and quantile regression. The problem with this technique is that only one point in the covariates distribution is considered: the mean. Differences in higher moments of the distribution of the independent variables are not controlled for. The second decomposition method, proposed by Machado and Mata (2002), combine quantile regression and a bootstrap approach to stochastically simulate counterfactual wage distributions. It does not have the same inconvenient as the first decomposition but requires estimating a large number of quantile regressions, which is computationally involved. In this study, the estimations were possible due to the relatively small number of observations. A less computer-intensive procedure is necessary in order to extend the field of application of this decomposition. A formal proof of the consistency of this estimator and its asymptotic distribution should also be the object of further research ${ }^{3}$.

The wage structure in the public and private sectors in West Germany has been examined using the data from the GSOEP for the years 1984-2000. Both decomposition methods give similar results. They indicate that the conditional pay distribution is more compressed in the public sector. The public sector wage premium is highest at the lower end of the wage distribution and then decreases monotonically as we move up the wage distribution. Thus, the public sector reduces within-group inequality. Mean results suggest that wages are about 8 percent lower in the public sector for males but substantially higher for females (about 8 percent).

Allowing the premium to be different for four categories of education, we find that the public sector reduces also the between-group inequality. Those with basic schooling obtain the highest public sector wage premium. The estimation of the premium by levels of experience suggests that the premium increases with the years of experience for women. Finally, we examine the evolution of the premium from 1984 to 2000 and find no trend or cycle. The wage structure seems to be extremely stabile.

Are these differences in wages between the public and private sector "true" premiums, or are there other factors at work? The differences may reflect unobserved individual characteristics. The results may also be biased as a result of omitted explanatory variables.

\footnotetext{
${ }^{3}$ Machado and Mata (2002) estimate the asymptotic distribution by a simple bootstrap of the generated samples but give no proof that the bootstrap is consistent.
} 
There may be "compensating differentials", such as working conditions and fringe benefits. All these issues as well as the problems of selectivity and endogeneity have not been explored in this study. Therefore, the results do not necessarily have a causal interpretation. Rather they provide a descriptive comparison of earnings distribution for public and private sector employees.

Quantile regression estimates show that the distribution of earnings is less dispersed for public than for private sector employees. This reduces the inequality of the wage structure but this may also have implications for how workers with different abilities and productivities sort between those sectors. Employees at the bottom of the wage distribution, especially among the less skilled, may decide to queue for relatively high-paying jobs in the public sector rather than take low-paid jobs in the private sector (Blackaby et al. 1996). This can lead to "wait" unemployment. Katz and Krueger (1991) have found empirical relevance for this prediction. On the other hand, the wage penalty at the upper end of the public sector pay scale is useful in explaining the exodus of senior managers to the private sector. Many observers have voiced concern that the government will be increasingly unable to recruit highly skilled employees such as scientists, engineers and judges. Reforms allowing for more vertical flexibility in the public sector wage structure seem to be especially important in order to link more closely wage rates to individual performance and underlying labor market conditions.

\section{References}

Bassett G, Koenker R (1978) An empirical quantile function for linear models with iid errors. Journal of the American Statistical Association 77:407-415

Becker G (1971) The economics of discrimination, $2^{\text {nd }}$ edition. University of Chicago Press, Chicago

Borjas GJ (1984) Electoral cycles and the earnings of federal bureaucrats. Economic Inquiry 22:447-459

Blackaby DH, Murphy PD, O'Leary NC (1996) Public-Private Sector hourly Earnings Differentials in the UK: A Decile-Based Decomposition of the QLFS. University of Wales Swansea, Department of Economics, Discussion Paper Series, No 96-16

Blau FD, Kahn LM (1992) The gender earnings gap: learning from international comparisons. American Economic Review 82:533-538

Blinder A (1973) Wage discrimination: reduced form and structural estimates. Journal of Human Resources 8:436-455

Buchinsky M (1991) The Theory and Practice of Quantile Regression. Ph. D. Dissertation, Harvard University

Buchinsky M (1998) Recent Advances in Quantile Regression Models: A practical guide for empirical research. Journal of Human Resources 33:88-126

Disney R, Gosling A (1998) Does it pay to work in the Public Sector? Fiscal Studies 19:347374

Dustman C, Van Soest A (1997) Wage Structures in the Private and Public Sectors in West Germany. Fiscal Studies 18:225-247

Dustman C, Van Soest C (1998) Public and private sector wages of male workers in Germany. European Economic Review 42:1417-41 
Ehrenberg RG, Schwarz JL (1986) Public Sector Labor Markets. In: Ashenfelter O, Layard R (eds.) Handbook of Labor Economics, Volume 2. Elsevier Science Publishers, Amsterdam, pp. 1219-1268

Federal Statistical Office (2001) Statistical Yearbook 2001 for the Federal Republic of Germany. Federal Statistical Office, Wiesbaden

Fitzenberger B (1998) The moving blocks bootstrap and robust inference for linear least squares and quantile regressions. Journal of Econometrics 82:235-287

García J, Hernández PJ, López-Nicolás A (2001) How wide is the gap? An investigation of gender wage differences using quantile regression. Empirical Economics 26:146-167

Gregory RG, Borland J (1999) Public Sector Labor Markets. In: Ashenfelter O, Card D (eds.) Handbook of Labor Economics, Volume 3c. Elsevier Science Publishers, Amsterdam, pp. 3573-3630

Katz LF, Krueger AB (1991) Changes in the Structure of Wages in the Public and Private Sectors. In: Ehrenberg R (ed.) Research in Labor Economics, Volume 12. JAI Press, Greenwich, pp. 137-172

Koenker R, Bassett G (1978) Regression Quantiles. Econometrica 46:33-50

Koenker R, Bassett G (1982) Robust tests for heteroscedasticity based on regression quantiles. Econometrica 50:43-61

Koenker R, Hallock K (2001) Quantile Regression: An Introduction. Journal of Economic Perspectives 15.4:143-156

Machado J, Mata J (2002) Counterfactual decompositions of changes in wage distributions using quantile regression. Mimeo, Universidade Nova de Lisboa

Mueller R (1998) Public-private sector wage differentials in Canada: evidence from quantile regressions. Economics Letters 60:229-235

Nielsen HS, Rosholm M (2001) The public-private sector wage gap in Zambia in the 1990s: A quantile regression approach. Empirical Economics 26:169-182

Oaxaca R (1973) Male-female wage differentials in urban labor markets. International Economic Review 14:693-709

Poterba J, Rueben K (1995) The Distribution of Public Sector Wage Premia: New Evidence Using Quantile Regression Methods. NBER Working Paper No. 4734

Smith S (1976) Pay differentials between federal government and private sectors workers. Industrial and Labour Relations Review 29:233-257

Smith S (1977) Equal Pay in the Public Sector: Fact or Fantasy. Industrial Relations Section, Princeton

SOEP Group (2001) The German Socio-Economic Panel (GSOEP) after more than 15 years Overview. In: Holst E, Lillard DR, DiPrete TA (eds.) Proceedings of the 2000 Fourth International Conference of German Socio-Economic Panel Study Users (GSOEP2000), Vierteljahrshefte zur Wirtschaftsforschung (Quarterly Journal of Economic Research), $70: 1$, pp. $7-14$ 


\section{Appendix}

Table A.1: Explanation of variables

\begin{tabular}{|c|c|}
\hline Variable & Description \\
\hline Wage & $\begin{array}{l}\text { Gross hourly earnings from employment. Gross hourly wage are derived by } \\
\text { dividing gross monthly earnings by monthly actual hours worked. }\end{array}$ \\
\hline Ln(wage) & The natural logarithm of wage. \\
\hline Expr & $\begin{array}{l}\text { Number of years of potential work experience the individual has } \\
\text { accumulated. It is measured by min(age-schooling-6, age }-18) \text {. }\end{array}$ \\
\hline Gender & Dummy; 1 if women. \\
\hline Tenure & Number of years with current employer \\
\hline Part-time & Dummy; 1 if the individual is part-time or marginally employed. \\
\hline Married & Dummy; 1 if married. \\
\hline Ed level & Ordered variable on education: \\
\hline Ed level 1 & Dummy; 1 if basic or intermediate schooling with no training or no degree. \\
\hline Ed level 2 & Dummy; 1 if basic schooling with apprenticeship. \\
\hline Ed level 3 & Dummy; 1 if intermediate schooling with apprenticeship. \\
\hline Ed level 4 & $\begin{array}{l}\text { Dummy; } 1 \text { if high school (Abitur or Fachabitur) with no training or with } \\
\text { apprenticeship. }\end{array}$ \\
\hline Ed level 5 & Dummy; 1 if high school with technical school or polytechnic. \\
\hline Ed level 6 & Dummy; 1 if university. \\
\hline Management & Dummy; 1 if occupation in management. \\
\hline Professional & Dummy; 1 if professional. \\
\hline Clerk & Dummy; 1 if clerk. \\
\hline Salesperson & Dummy; 1 if salesperson. \\
\hline Service worker & Dummy; 1 if service worker. \\
\hline Agriculture & Dummy; 1 if occupation in agriculture. \\
\hline Blue collar & Dummy; 1 if blue collar. \\
\hline Others & Dummy; 1 if occupation in others categories. \\
\hline Psect & Dummy; 1 if employed in the public sector. \\
\hline
\end{tabular}


Table A.2: Descriptive statistics, means

\begin{tabular}{|c|c|c|c|c|c|c|c|c|c|}
\hline \multirow[t]{2}{*}{ Variable } & \multicolumn{3}{|c|}{ All observations } & \multicolumn{3}{|c|}{ Men } & \multicolumn{3}{|c|}{ Women } \\
\hline & All & $\begin{array}{l}\text { Public } \\
\text { Sector }\end{array}$ & $\begin{array}{l}\text { Private } \\
\text { Sector }\end{array}$ & All & $\begin{array}{l}\text { Public } \\
\text { Sector }\end{array}$ & $\begin{array}{l}\text { Private } \\
\text { Sector }\end{array}$ & All & $\begin{array}{l}\text { Public } \\
\text { Sector }\end{array}$ & $\begin{array}{l}\text { Private } \\
\text { Sector }\end{array}$ \\
\hline Ln(wage) & 3.15 & 3.22 & 3.12 & 3.28 & 3.33 & 3.27 & 2.97 & 3.11 & 2.91 \\
\hline Experience & 20.50 & 21.28 & 20.23 & 20.71 & 22.36 & 20.22 & 20.22 & 20.18 & 20.24 \\
\hline Gender & 0.44 & 0.50 & 0.41 & & & & & & \\
\hline Tenure & 10.34 & 12.92 & 9.44 & 11.73 & 15.41 & 10.64 & 8.54 & 10.42 & 7.74 \\
\hline Married & 0.62 & 0.65 & 0.61 & 0.64 & 0.68 & 0.63 & 0.59 & 0.61 & 0.58 \\
\hline Part-time & 0.22 & 0.27 & 0.20 & 0.05 & 0.07 & 0.04 & 0.45 & 0.48 & 0.44 \\
\hline Education: & & & & & & & & & \\
\hline Ed level 1 & 0.08 & 0.05 & 0.09 & 0.07 & 0.02 & 0.08 & 0.11 & 0.09 & 0.11 \\
\hline Ed level 2 & 0.36 & 0.26 & 0.39 & 0.40 & 0.30 & 0.43 & 0.31 & 0.22 & 0.34 \\
\hline Ed level 3 & 0.26 & 0.30 & 0.25 & 0.21 & 0.26 & 0.19 & 0.34 & 0.33 & 0.34 \\
\hline Ed level 4 & 0.08 & 0.07 & 0.08 & 0.08 & 0.06 & 0.08 & 0.08 & 0.08 & 0.08 \\
\hline Ed level 5 & 0.10 & 0.12 & 0.09 & 0.12 & 0.13 & 0.11 & 0.08 & 0.12 & 0.06 \\
\hline Ed level 6 & 0.12 & 0.19 & 0.09 & 0.14 & 0.22 & 0.11 & 0.09 & 0.16 & 0.06 \\
\hline Occupation: & & & & & & & & & \\
\hline Professional & 0.23 & 0.36 & 0.18 & 0.23 & 0.32 & 0.21 & 0.22 & 0.40 & 0.14 \\
\hline Management & 0.04 & 0.02 & 0.04 & 0.06 & 0.03 & 0.06 & 0.01 & 0.02 & 0.01 \\
\hline Clerk & 0.28 & 0.32 & 0.27 & 0.18 & 0.26 & 0.16 & 0.40 & 0.37 & 0.42 \\
\hline Salesperson & 0.08 & 0.01 & 0.11 & 0.05 & 0.02 & 0.07 & 0.12 & 0.00 & 0.17 \\
\hline Service Worker & 0.09 & 0.18 & 0.07 & 0.06 & 0.18 & 0.03 & 0.14 & 0.17 & 0.12 \\
\hline Agriculture & 0.01 & 0.01 & 0.02 & 0.02 & 0.01 & 0.02 & 0.01 & 0.01 & 0.02 \\
\hline Blue collar & 0.25 & 0.09 & 0.30 & 0.38 & 0.16 & 0.44 & 0.08 & 0.02 & 0.10 \\
\hline Others & 0.02 & 0.03 & 0.02 & 0.02 & 0.03 & 0.02 & 0.02 & 0.03 & 0.01 \\
\hline $\begin{array}{l}\text { Number of } \\
\text { observations }\end{array}$ & 2972 & 770 & 2202 & 1677 & 386 & 1291 & 1295 & 384 & 911 \\
\hline
\end{tabular}

